\title{
ALGUMAS CONSIDERAÇÕES SOBRE AS TECNOLOGIAS DE INFORMAÇÃO COMO FOR- ÇA INTEGRADORA PARA O MERCOSUL
}

\author{
Ariadne Chloë Furnival
}

Resumo

Aborda à luz de pesquisas já desenvolvidas por outros autores que apontam para as redes como mecanismos que meramente reforçam as desigualdades globais existentes. Apresenta o potencial papel das redes eletrônicas de informação e redes interfirmas como fator determinante para maior integração e cooperação entre os países dentro e fora do Mercosul.

\section{Palavras chave}

Mercosul; Mercados eletrônicos; Redes interfirmas; Redes eletrônicas de informação.

\section{INTRODUÇÃO}

Há uma tendência predominante de se acreditar que as redes, e em particular, as redes eletrônicas, são intrinsecamente "abertas", democráticas por natureza, e livremente acessíveis para todos que escoIham participar delas (vide, por exemplo, STREETER et. al., 1996). Entretanto, há certos estudiosos e, sobretudo, aqueles escrevendo da perspectiva dos países "menos desenvolvidos" (LDCs - less developed countries), que são de outra opinião - diga- mos, mais realista - , alegando que, na verdade, as redes existentes são altamente exclusivas e de difícil acesso, e que, consequentemente, mantêm e consolidam no plano virtual, uma situação de monopólio e concentração de capital que beneficia, de forma significativa, somente certas regiões do mundo, "deixando para trás" outras.

Este trabalho constitui uma tentativa de reunir e revisar algumas fontes da literatura - principalmente das áreas de políticas tecnológicas-industriais, e da economia - consideradas relevantes para o debate acerca de mercados de informação e o 
Mercosul. Serão apresentadas seções que tratam dos conceitos de mercados e custos de transações em mercados, seguidas por breves discussões em seções sobre o papel das tecnologias da informação (Tls) nos mercados eletrônicos e sobre redes "interfirmas". Daí, retomando o ponto levantado no início desta introdução, serão abordados os diferentes tipos de barreiras que as redes apresentam. $O$ trabalho fechará com uma breve discussão das implicações dessas questões para o Mercosul, à luz de algumas características estruturais deste mercado regional.

A revisão é de relevância à questão de mercados de informação, embora o trabalho não trate especificamente do setor de serviços de informação: optou-se por um enfoque mais "macro" e "infra-estrutural", tomando como ponto de partida o fato indiscutível de que os avanços em tecnologias de informação e telecomunicações estão afetando dramaticamente as estruturas de firmas e mercados, permitindo uma integração mais intensa entre as diferentes etapas adjacentes na cadeia de valor agregado, tanto entre organizações quanto entre países. Ou seja, qualquer debate sobre o futuro estruturamento de mercados dentro do Mercosul deve tomar como premissa que, como afirmam Jussawalla e Cheah (1984, p.68), já está bem sedimentado um novo "regime internacional", em que as tecnologias de informação e comunicação assumem o controle das atividades econômicas dentro de, e entre, países.

\section{MERCADOS E CUSTOS DE TRAN- SAÇÃO}

Os dois mecanismos básicos para coordenar o fluxo de materiais e serviços numa economia são mercados e hierarquias (MALONE; YATES; BENJAMIN, 1987).
A função principal de um mercado é a de coordenar o fluxo das forças de oferta e procura e de coordenar as transações externas entre indivíduos e firmas. Assim, os atributos como design, preço, quantidade, prazo de entrega etc. são determinados pelas forças de mercado. Do outro lado da equação, temos os compradores/consumidores, que podem comparar os bens e serviços sendo oferecidos no mercado, usando os atributos listados acima (entre outros) como critério de tomada de decisão acerca de qual bem ou serviço seria o melhor.

Em relações hierárquicas, os compradores somente trabalham com um fornecedor predeterminado, e são as decisões da alta gerência, não as forças de mercado, que vão determinar esses atributos. Por exemplo, no caso de um único fornecedor servindo um ou mais compradores como a única fonte de um determinado bem ou serviço, a relação tende a ser hierárquica, ao passo que a relação entre um comprador e múltiplos fornecedores é governado pelas forças do mercado.

A vantagem evidente da estrutura de mercado, então, é de que dá mais poder decisório ao comprador, que pode escolher o bem com a combinação mais interessante para suas finalidades pessoais, de preço, design etc. Entretanto, os custos de coordenação relacionados a esse escopo de opções são mais altos daqueles de uma estrutura hierárquica. Enquanto o conceito de custos de produção refere-se aos custos de matérias primas, de processos produtivos, de transporte de bens primários e manufaturados, os custos de coordenação se referem aos custos de transações "de todo o processamento de informação necessária para a coordenação do trabalho de pessoas e máquinas que desempenham os processos primários" (MALONE; YATES; BENJAMIN, 1987, p.485). Alguns exemplos de atividades de coordenação num merca- 
do que implicam custos são a seleção de compradores, determinação de preços e design, cronograma de entrega, negociação de contratos, pagamento de contas etc. Por exemplo, um contrato de software a ser desenvolvido por terceiros incorre custos de transação, que resultam do processamento da transação no mercado, mas são custos que não podem aumentar o valor intrínseco do software (GURBAXANL; WHANG, 1991). Outro exemplo da incorrência de custos de transação seria na designação de direitos de privacidade a indivíduos, requerendo sua permissão antes da disseminação de dados pessoais. Existiriam custos de transação substanciais (e justificáveis, no caso), em qualquer contrato multilateral entre o vendedor de dados e grupos de indivíduos.

Devido a estes tipos de custos de transação, muitas firmas em relações do mercado de fornecedor-comprador, procuram resolver o problema se integrando verticalmente (o que significa que atividades distintas da cadeia produtiva são internalizadas na firma, ao invés de serem empreendidas por firmas terceiras), tornando a estrutura mais característica de uma hierarquia, nas quais os custos de transação são evidentemente menores daqueles de um mercado.

Vemos então, como as estruturas de mercados, por natureza, são intensivas em atividades de coordenação, e portanto, em mecanismos de comunicação de informação entre os vários atores. Hayek (apud GURBAXANL; WHANG, 1991) se entusiasma das "maravilhas dos mercados" embutidas no seu sistema de preços, pois é via esse sistema que o mercado coleta e transmite conhecimentos de circunstâncias de tempo e lugar que nenhum autoridade central poderia centralizar. Dessa maneira, afirmam Gurbaxanl e Whang (1991, p.63), "o mercado é, ele mesmo, um siste- ma de informação que serve a economia inteira".

\section{O PAPEL DAS TECNOLOGIAS DE INFORMAÇÃO EM MERCADOS}

As tecnologias de informação (TIs) têm o grande potencial de reduzir dramaticamente os custos de coordenação (ou os "custos de transação") nas estruturas de mercados, dado que, como nota Malone, Yates, Benjamin (1987, p.486) "a essência da coordenação envolve comunicação e processamento da informação". Historicamente, a difusão de mercados em termos geográficos, que implicava no aumento substancial do número de atores econômicos interagindo, era acompanhado por avanços primeiro em transporte, e depois, em tecnologias de comunicação e Tls. Malone, Yates, Benjamin (1987) apontam para três fenômenos relacionados à disseminação crescente de TIs na coordenação das atividades de mercados: o efeito de comunicação eletrônica, o efeito de integração eletrônica e o efeito de brokerage eletrônico. O primeiro refere-se à possibilidade de se comunicar quantidades cada vez maiores de informações por custos crescentemente menores e o segundo se refere à noção do uso de TIs para - além de apressar a comunicação - integrar de forma mais intensa, os processos que usam e criam informação. O just-in-time é um bom exemplo desse efeito de integração eletrônica. O terceiro efeito reside no conceito do broker como sendo um agente que tem contato com muitos potenciais fornecedores e compradores, colocando-os em contato um com outro, após fazer um matching (emparelhamento) dos requisitos procurados. O brokerage eletrônico, então, conecta esses compradores e fornecedores via meios computacionais, permitindo, ao mesmo tempo, um aumento no número de opções a serem consideradas, mas reduzin- 
do os custos do processo de seleção. Ou seja, o potencial desvantagem dos mercados do que os compradores podem sentir "inundados" pela grande quantidade de informação disponível para a tomada de decisão, é amenizada pela filtragem realizada pelo broker.

\section{MERCADOS ELETRÔNICOS E RE- DES INTER-FIRMAS}

Como delineado na seção anterior, a literatura aponta para a associação entre o crescente uso de TIs (com base nas telecomunicações), e uma mudança geral na direção de atividades econômicas sendo coordenadas por estruturas de mercados - mercados eletrônicos, no caso. Um efeito claro de tal tendência também pode ser percebido no aumento substancial em atividades (sobretudo, aquelas relacionadas aos arranjos de compartilhamento de informação) entre firmas (GURBAXANL; WHANG, 1991). Na Itália, por exemplo, a partir da década de setenta, o desenvolvimento impressionante da chamada "Terceira Itália" (na região nordeste e central do país) chamou a atenção de muitos economistas e cientistas sociais. Ficou evidente que a proliferação e sucesso econômico (tanto no mercado doméstico quanto no mundial) de muitas pequenas e médias empresas (PMEs) da região, se deveu muito ao fenômeno de "industrial clustering" (HUMPHREY; SCHMITZ, 1996) — ou seja, a concentração de firmas dos mesmos setores nas mesmas localidades. Em tais arranjos - mais tarde conhecidos como "distritos industriais" - existe uma proximidade entre os fornecedores de matérias primas, produtores de componentes, fornecedores de equipamentos e os produtores dos bens acabados. A atenção dada ao caso italiano levou ao surgimento de muitos distritos industriais e "clusters" industriais nos países em desenvolvimento, inclusive nos países latino-americanos (por exemplo os clusters de indústrias de calçados no Vale do Sinos, Brasil; Trujillo no Peru, e em Leon e Guadalajara, no México).

Já existe uma literatura vasta que trata do assunto. Abordaremos agora, o tema de redes de firmas - estreitamente relacionado ao fenômeno de "clusters" industriais - e a questão de se representam ou não uma potencial "janela de oportunidade" para os países em desenvolvimento, e no caso, a região que engloba o Mercosul.

\section{REDES E BARREIRAS DE ENTRA- DA A ELAS}

O discurso atual, e bastante popularizado no auge da Internet, aponta para as redes como sendo estruturas intrinsecamente abertas e dinâmicas, em estado de reconfiguração contínua, pois evidenciam livre trânsito de saída e entrada dos "afiliados", e não possuem centros ou nós dominantes. As inúmeras vantagens que essas características "democráticas" das redes podem trazer aos seus integrantes são geralmente enfatizadas, com questões pragmáticas referentes aos custos de entrada e saída sendo não-problematizadas. Porém, há evidência que aponta para a verdade que a maioria das redes configuradas no âmbito de produção global - desde redes de pesquisa até redes de comercialização são, de fato, fechadas e centralizadoras quanto à sua penetração pelos países denominados "menos desenvolvidos" (less developed countries - LDCs). Tomando-se como exemplo o que Ernst (1994) denomina de "redes tecnológicas" — ou seja, aquelas redes relacionadas à Pesquisa e Desenvolvimento (P\&D) -, Freeman e Hagedoorn (1994) mostram que tais redes se iniciam e se concentram nos, e são dominadas pelos, países desenvolvidos. A partir de dados da década de 80 (e pouco 
indica que a situação é distinta hoje), estes autores notam que mais que $95 \%$ das alianças estratégicas tecnológicas se constituíram entre as firmas dos países desenvolvidos. Há uma pequena fração dessas alianças $(2,3 \%)$ entre firmas dos países desenvolvidos com firmas dos LDCs, sendo elas predominantemente nos setores de baixa agregação tecnológica (por exemplo, bebida e alimentos). Freeman e Hagedoorn (1994) ainda notam que acordos de transferência de tecnologia - uma atividade complementar e não apenas uma alternativa ao desenvolvimento tecnológico, pois acarreta em aprendizagem tecnológica - também são concentrados entre os países desenvolvidos.

Se a própria configuração das redes frente à escolha de países parceiros na rede constitui-se num obstáculo bastante tangível aos países em desenvolvimento, Ernst (1994) enumera outras barreiras de entrada dos vários tipos de redes (redes de consumidores, fornecedores, produtores, além das tecnológicas) na produção de produtos e serviços. Há custos altos de entrada a uma rede de informação, em termos de investimentos em infra-estrutura (principalmente computacional) para se tornar um nó de rede, custos de treinamento de recursos humanos para se ajustar à nova dinâmica de trabalho exigida por networking, e custos substanciais para se manter numa rede. Além do mais, o alto grau de normalização de equipamentos e software de uma dada rede implica que os custos de sair da rede (para, por exemplo, se transferir a outra mais favorável às atividades de uma dada organização) são também muito elevados. Aqui vale a pena ressaltar que, ao mesmo tempo que a posse das Tls de ponta são consideradas cada vez mais essenciais ao uso ótimo de informação no processo de produção, as indústrias que produzem o hardware e software de comunicação, por exemplo, satélites, sistemas di- gitais de telefones, microprocessadores, fibra óticas etc., além das firmas que se especializam em serviços de processamento, armazenamento e recuperação de dados em grande escala, se mantêm concentradas nos países desenvolvidos. Como notam Jussawalla e Cheah (1984), embora a importação de tais tecnologias seja mais efetivo em termos de custos ("cost effective") para os LDCs, a perpetuação dessa gap informacional constitui uma nova forma de colonialismo. Entretanto, longe de serem receptores passivos das tecnologias estrangeiras, os LDCs absorvem ativamente as tecnologias, adaptando e aperfeiçoando-as. Schmitz (1984) e Lall (1994) também notam uma relação entre o grau da aprendizagem tecnológica que ocorrerá e a própria forma de adquirir a tecnologia: a aprendizagem terá mais chance de ser "profunda" se a tecnologia for comprada "à distância/externalizada" (arm's length), quando o controle da tecnologia é apropriado pelo país comprador, muito diferente de uma compra "internalizada" (a forma mais comum sendo o investimento estrangeiro direto - FDI), pela qual o vendedor mantém o controle da tecnologia, permitindo, assim, apenas uma aprendizagem mais superficial.

Ernst (1994) também aponta para outro tipo de obstáculo de entrada a rede: a saber, o fato de que muitas delas são dominadas pelas corporações que as estabelecem, que "se enredam" justamente para consolidar oligopólios, alegando que "o desejo de consolidar oligopólios estabelecidos provavelmente tem sido a força

\footnotetext{
1 “..the desire to consolidate established oligopolies probably has been the main driving force between the current wave of network transactions in OECD countries" (OECD = Organization for Economic Cooperation \& Development - associação de 21 nações - de países desenvolvidos - estabelecido em 1961, para promover crescimento e comércio entre elas.
} 
estimuladora principal entre a onda atual de transações em rede nos países OECD". ${ }^{1} \mathrm{Fi}-$ nalmente, Ernst (1994) enfatiza que, sobretudo com respeito às redes que interligam os produtores aos fornecedores, ao invés de descentralizar o poder de tomada de decisão e imposição de condições, estas redes em particular acarretam na transferência do ônus de investimento em P\&D, equipamentos sofisticados e capacitação de recursos humanos dos produtores/ montadores, para os fornecedores (em geral, PMEs), que sofrem assim, o fenômeno de "lock-in" (ficar preso) à rede, no sentido que se tornam de certa forma dependentes das grandes produtores, que podem, a qualquer momento, decidir cortar certos vínculos com esses nós "pequenos" quando não há mais vantagens da vinculação. Ernst (1994) nota que no setor de peças automobilísticas na Alemanha, por exemplo, os pequenos fornecedores de peças ficaram particularmente vulneráveis às exigências acirradas dos montadores, acarretando falências de muitas PMEs fornecedoras, apontando para a afirmação de que a associação entre mais redes de produção e mais cooperação é exagerada.

Além dos obstáculos de entrada às redes que são mais inerentes à própria formação e dinâmica do funcionamento das mesmas, existem outros obstáculos à própria constituição inicial de redes, relacionados mais a fatores inerentes à estrutura histórica-econômica dos países periféricos. Por exemplo, Perez $(1994 ; 1996)$ aponta para a influência negativa da herança de políticas de industrialização de substituição de importações (ISI) como uma herança que semeava um sentimento geral de confronto e não-confiança entre produtores e provedores - exatamente o contrário do espírito das interações necessárias para o funcionamento eficaz de redes, que deveriam ser, como Humphrey e Schmitz (1996) nos mostram interações de confiança ("trust") que acompanham a crescente interdependência entre firmas. Com a proteção dos respectivos governos latino-americanos, essas interações se caracterizavam, nas palavras de Perez (1996, p.356), como sendo "a punta de pistola":

"Las políticas para promover la sustitución de importaciones 'aguas arriba' se basaron en convertir a los productores finales, públicos e privados, en un mercado cautivo para los proveedores. Usualmente se forzaba a las empresas nacionales a comprar los insumos o biens de capitla producidos en el país, cualesquiera que feseen el precio o la calidade."

Tal ambiente fortaleceu a criação de associações e indústrias nitidamente separadas nos vários setores - uma segmentação cujos efeitos negativos exigirão esforço político substancial para serem superados. Entretanto, como nota Perez (1996), esta intervenção governamental tem sido, em geral, a favor dos fornecedores, mas ao mesmo tempo, não tem colocado pressão nos mesmos para melhorar sua produtividade e qualidade, o que serve para agravar relações fornecedor-produtor. Interconexões eletrônicas implementadas sob tais condições levariam mais provavelmente ao estabelecimento de hierarquias eletrônicas, nas quais as opções para o comprador são mais reduzidas, e assim, o fornecedor tem mais "poder" na interação.

Podemos resumir aqui que, na medida em que as redes apresentem a oportunidade de países ou regiões fortalecerem suas vantagens comparativas, pois permitem verticalização por via de maior integração de atividades especializadas da cadeia produtiva, representam também 
oportunidades cada vez mais raras para os LDCs, e isto devido tanto à sua já consolidada "exclusão" das redes mundiais, quanto à sua herança histórico-econômica.

\section{CONSIDERAÇÕES FINAIS; REDES E O MERCOSUL}

Será que é possível alegar agora que o problema dos LDCs sendo bastante excluídos das redes dos vários tipos de atividades interfirmas e interpaíses vai ser amenizado pela consolidação do Mercosul? Ou seja, não seria o caso que o Mercosul representa uma janela de oportunidade para os países da região fortalecerem a cooperação entre eles? Evidentemente, esperamos que sim. Entretanto, há de se demonstrar cautela em afirmar que tal tipo de interação caracterizará não inequivocamente a integração da região. $E$ a razão de tal cautela reside na natureza do modelo do Mercosul, que, para Ferrer (1997), é de uma extensão da inserção internacional no processo da globalização (ou, como afirma Guerra-Borges (1996, p.439), "Se trata de regionalizar a globalização" ${ }^{2}$, e como tanto, os países membros ficam sujeitos às premissas centrais do modelo neoliberal em que a globalização tem se pautado.

Uma crença central do neoliberalismo é que intervenções do Estado na forma de políticas (por exemplo, industriais, tecnológicas - ou seja, especificamente setoriais), deveriam ser evitadas, para que o mercado possa atingir seu "ótimo", a mais próxima possível da "perfeição", onde não haveriam distorções introduzidas a partir de tais intervenções do Estado. Um mecanis-

\footnotetext{
${ }^{3}$ Ernst (1994, p.114) nota que: "o que hoje é denominado cooperação sul-sul talvez seja, de fato, dirigida pela lógica das estratégias de globalização seguidas por organizações norteamericanas, japonesas e européias."
}

mo empregado para induzir a "perfeição" de um mercado é a redução de barreiras a importações - mas em geral, os LDCs são induzidos a eliminar suas barreiras, apesar de dívidas externas já pesadas, sem terem a garantia que os países industrializados concederão vantagens recíprocas para os produtos dos LDCs. Assim, seguindo Ferrer (1997, p.348), tal estratégia neoliberal "aprofunda a vunerabilidade histórica de desenvolvimento" dos países da região, e sobretudo porque a estratégia se pauta no reforço da especialização dos países exportadores de produtos primários (uma manifestação da divisão internacional de trabalho), o que evidentemente coloca estes países em situações de grande desvantagens em relação à balança de pagamentos. Além do mais, continua Ferrer (1997, p.350), existe uma divisão de trabalho intraregional, com base nas vantagens comparativas estáticas, que "reproduz dentro da região o modelo centro-periferia", com um país como o Brasil se especializando em produtos manufaturados e intensivos em conhecimento, e a Argentina em exportações de alimentos, energia e matérias primas (FERRER, 1997).

Finalmente, como nota Ernst (1994, p.114), a cooperação sul-sul não bastará, pois com as forças do mercado globalizado norteando tal cooperação, os países do sul, e no caso, do Mercosul, entrarão em contato "prematuro" com a concorrência internacional - contato este que destruirá as capacidades tecnológicas do setor informacional (como de outros) já existentes. Assim, continua a argumentação desse autor, há justificativas boas para promover intervenções políticas dos respectivos governos para abrandar os efeitos prejudicais da abertura. Tais intervenções poderiam incluir incentivos para indústrias emergentes ("infant industries"), sobretudo para aquelas que exportam, tarifas e restrições de quantidades de bens e materiais 
importados, implementação de leis de similares ("laws of similars" - restringindo a importação de bens similares àqueles já manufaturados localmente), restrições de "conteúdo local" - controlando a importação de matérias primas disponíveis localmente, e facilitando a disponibilidade de financiamento nos bancos governamentais.

Entretanto, a cooperação sul-sul terá que manter, sim, vínculos fortes com as redes norte-sul, principalmente para se manter uma forma de acesso ao know-how internacionalmente disponível (ERNST, 1994, p.114). Dessa forma, alguns economistas da CEPAL (1994) enfatizam que, para os anos noventa, as políticas industriais dos países latino-americanos precisam concentrar muito mais na difusão das tecnologias já disponíveis para que as indústrias dos países do sul possam chegar mais rapidamente ao nível das "melhores práticas" da fronteira tecnológica internacional, do que concentrar esforços numa política que invista pesadamente em $P \& D$, que às vezes, segundo Guimarães (1993), se desloca inteiramente das necessidades do setor produtivo, concentrando-se, por exemplo, em projetos de prestígio (por exemplo, militares) com objetivos horizontais (ou seja, não especificamente de certos setores) e "vagos" do tipo que promovem a "soberania nacional" como prioridade.

\section{REFERÊNCIAS}

CEPAL, Reestruturación y desarrollo productivo: desafio y potencial para los años noventa. Estudios e informes de la CEPAL. Santiago de Chile: Nações Unidas, 1994.

ERNST, D. Network transactions, market structure and technology diffusion implications for south-south co-operation. In: MYTELKA, L.K. (ed.), South-south cooperation in a global perspective. Paris: OECD, 1994, p.89-124.

FERRER, A. El Mercosur: entre el Consenso de Washington y la integración sustentable. Comércio Exterior. v.47, n.5, México, mayo, 1997, p.347-354.

FREEMAN, C; HAGEDOORN, J. Catching up or falling behind: patterns in international interfirm technology partnering. World Development, v.22, n.5, 1994.

GUIMARÃES, E. A. A experiência brasileira de política científica e tecnológica e o novo padrão de crescimento industrial. Texto pra discussão IEI-UFRJ, no. 296, abril, 1993, Rio de Janeiro.

GURBAXANI, V.; WHANG, S. The impact of information systems on organizations and markets. Communications of the ACM Jan. 1991, v.34, n.1, p.59-73.

GUERRA-BORGES, A. Globalização de la regionalización en América Latina: un punto de vista alternativo. Comércio Exterior. v.46, n.6, México, junio, 1996, p.436-442.

HUMPHREY, J; SCHMITZ, H. Trust and economic development. IDS Discussion Paper, no. 355, Sussex, Inglaterra, August 1996.

JUSSAWALLA, M.; CHEAH, C-W. International trade and information: some 
welfare implications. In: JUSSAWALLA, M.; EBENFIELD, $\mathrm{H}$. (eds.) Communication and information economics: new perspectives. Information Research and Resource Reports Vol. 5. Amsterdam: North-Holland, 1984.

LALL, S. Industrial policy: the role of government in promoting industrial and technological development. In: UNCTAD Review, 1994.

MALONE, T.W; YATES, J; BENJAMIN, R.I. Electronic markets \& electronic hierarchies. Communications of the ACM June 1987, v.30, n,6, p.484-497.

PEREZ, C. Technical change and the new context for development. In: MYTELKA, L.K (ed.) South-south co-operation in a global perspective. Paris: OECD, 1994, p.55-87.

PEREZ, C. La modernización industrial en América Latina y la herencia de la sustitución de importaciones. Comércio Exterior, México, mayo, 1996, v.46, n.5, p.347-363.

SCHMITZ, H. Industrialisation strategies in less developed countries: some lessons of historical experience. In: KAPLINSKY, R. (ed), Third world industrialization in the 80s: open economies in a closing world. London: Frank Cass, 1984.

STREETER, L.A.; KRAUT, R.E; LUCAS, Jr., H.C; CABY, L. How open data networks influence business performance and market structure. Communications of the $A C M$, v.39, n.7, July 1996, p.63-73.

\section{Ariadne Chloë Furnival}

Professora Assistente no Departamento de Ciência da Informação, Universidade Federal de São Carlos (UFSCar); Doutoranda no Departamento de Políticas Científicas e Tecnológicas do Instituto de Geociências, UNICAMP.

(e-mail: chloe@power.ufscar.br)

\section{Title}

Some considerations on information technologies as an integrating force for Mercosur Common Market

\section{Abstract \\ The potential role of electronic information networks and inter-firm networks as a determining factor for greater integration and cooperation between countries within and beyond the Mercosur Common Market is dealt with in the light of the research carried out by the authors, who point to these networks as mechanisms that merely reinforce the already- existing global inequalities.}

\section{Keywords}

Mercosur; Electronic Markets; Inter-firm Networks.

\section{Titulo}

Algunas consideraciones sobre las tecnologias de información como fuerza integradora para el Mercosur 


\section{Resumen}

Aborda, a la luz de investigaciones ya desarrolladas por otros autores que señalan las redes como mecanismos que simplemente refuerzan las desigualdades globales existentes. Presenta el papel potencial de las redes electrónicas de información y redes interfirmas ("Empresas") como factor determinante para mayor integración y cooperación entre países dentro y fuera del Mercosur.

\section{Palabras-Clave}

Mercosur; Mercados Electrónicos; Redes Interfirmas; Redes Electrónicas de Información

Artigo recebido em: 30/04/98 